\title{
Effects of Treadmill Training with Kinesio Taping of Tibialis Anterior on Muscle Function, Tibialis Anterior Muscle Strength, and Gait Ability in Poststroke Patients
}

\author{
Kyunghun Kim ${ }^{a} \oplus$, Taesung $\operatorname{In}^{\mathrm{a}^{*}(\mathbb{D}}$, Donghoon $\mathrm{Kim}^{\mathrm{a}^{\star}(\mathbb{1})}$

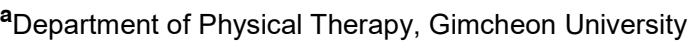 \\ *These authors contributed equally to this work
}

Objective: Stroke patients generally have problems with motor function, muscle weakness, and gait.This study was purposed toevaluate the effect of the treadmill training with kinesio taping of tibialis anterior (TKT) on muscle function, tibialis anterior, muscle strength, and gait ability in poststroke patients.

Design: A randomized controlled design

Methods: The participants were randomly divided in the TKT group (experimental group) and treadmill training with sham kinesio taping (control group), with 21 patients assigned to each group. Both groups receive treadmill training with kinesio taping and sham kinesio taping for 30 minutes per day, five days per week, for four weeks. The motor function was measured using the Fugl-Meyer assessment. A disital manual muscle test and G-walk were used to evaluate ankle dorsiflexor and gait ability.Evaluation was performed baseline and 4 weeks after the experiment.

Results: Both groups showed significantly more improvement in muscle function, tibialis anterior muscle strength, cadence, gait velocity, and stridelength in pre-post intervention change $(\mathrm{p}<0.05)$. The experimental group showed significantly more improvement in motor function, muscle strength, cadence, gait velocity, and stridelength ability comparedto the control group(p $<0.05)$.

Conclusions: These finding show the benefits of treadmill training with kinesio taping for functional recovery in poststroke patients

Key Words: kinesio taping, treadmill, motor, gait, stroke

\section{서론}

뇌졸중 환자는 비대칭적 근력 약화, 하지의 기능장애, 자세 동요, 자세 정렬, 체중의 무게 중심 이동 능력이 감 소되어[1], 이러한 제한적인 요소를 해결하여 뇌졸종 환자

의 보행능력을 향상하는 것이 중요하다[2,3].

트레드밀 훈련은 뇌졸중 환자의 하지 기능과 보행능력 을 증진시키기 위해 사용하는 중재 방법이다[4.5]. 단기간 하지의 자극을 통하여 중추신경계 운동 신경로의 민감성 을 변화시키며[6], 보행의 자동성을 유발시키는 방법으로 반복적인 트레드밀 보행훈련을 통해 율동적인 움직임을
촉진시켜 자동적인 움직임을 활성화한다[7,8]. 트레드밀 보행훈련의 효과는 평지 보행훈련 보다 뇌졸중 환자의 손 상측 하지의 체중지지 기간이 증진되어 대칭적인 보행패 턴 개선, 저측 굽힘근 경직감소 그리고 보행능력에 효과 적이라고 보고하였다[9].

키네시오 테이핑(kinesio taping; KT)은 약화된 근육 강화, 관절 불안정성 및 근육 긴장도 조절, 자세 정렬 보 조, 통증 조절, 과도한 근육 긴장 완화, 활동 범위 개선 등 다양한 질병의 재활 프로그램에서 사용되고 있다 $[10,11]$. 피부와 접촉된 키네시오 테이핑은 피부수용기와 고유수용 성 감각을 강하게 전달하여 관절과 근육의 바른 정렬을

Received: Aug 19, 2021 Revised: Sep 7, 2021 Accepted: Sep 8, 2021

Corresponding author: Taesung In (ORCID https://orcid.org/0000-0002-7672-5150)

Department of Physical Therapy, Gimcheon University [39528]

Tel: +82-10-2979-8386, Fax: +82-54-420-4467, E-mail :20160072@gimcheon.ac.kr

This is an Open-Access article distributed under the terms of the Creative Commons Attribution Non-Commercial License (http://creativecommons.org/licenses/ by-nc/4.0) which permits unrestricted non-commercial use, distribution, and reproduction in any medium, provided the original work is properly cited.

Copyright @ 2021 Korean Academy of Physical Therapy Rehabilitation Science 
촉진하여 균형과 보행능력이 향상된다고 보고하였다[12]. 하지의 고유수용성 감각입력은 뇌졸중 환자의 근력과 보 행기능과 관련이 있다[13]. 뇌졸중 33 명을 대상으로 앞정 강근과 발목 관절에 키네시오 테이핑을 적용한 그룹, 위 약 테이핑을 적용한 그룹, 대조군으로 나누어 즉각적인 효과를 알아본 결과, 키네시오 테이핑 적용한 그룹이 나 머지 두 그룹보다 균형과 이동능력에서 통계적으로 유의 한 차이가 있다고 보고하였다[14]. Yijuan 등[15]의 체계 적 고찰 연구를 살펴보면, 키네시오 테이핑 훈련은 일반 적인 물리치료 보다 하지의 운동기능, 균형, 그리고 보행 능력에 유의한 효과가 있다고 보고하였다. 치료적 효과는 통증감소, 근력강화, 혈액순환, 그리고 비정상적인 근긴장 도 완화시킨다고 보고하였다[16]. 또한 키네시오 테이핑 은 통증과 보행 패턴 개선을 위해 임상에서 치료방법으로 사용되고 있다[17,18].

트레드밀의 훈련과 키네시오 테이핑의 고유수용성 감 각 입력은 뇌졸중 환자의 기능 회복을 향상시키기 위해 중요한 요소이다. 그리고 지금까지의 선행 연구들은 키네 시오 테이핑이 뇌졸중 환자에게 긍정적인 영향을 미친다 는 연구가 있지만, 트레드밀 보행훈련과 키네시오를 병행 한 선행연구들은 부족한 실정이다.

따라서 본 연구의 목적은 키네시오 테이핑을 병행한 트 레드밀 보행훈련이 뇌졸중 환자의 운동기능, 하지 근력, 그리고 보행능력에 미치는 효과를 알아보고자 한다.

\section{연구방법}

\section{연구대상}

본 연구의 실험설계는 무작위 대조군 실험연구이다. 경 기도에 위치한 $\mathrm{K}$ 재활 병원에 입원 중인 뇌졸중 환자를 42 명을 대상으로 실험을 진행하였다. 선정 조건은 다음과 같다. 1) 뇌졸중 발병 후 6개월이 지난 자 2) 최소 독립적 인 보행이 가능한 자, 3) MMSE-K 24점 이상인 자, 4) 브 룬스트룸 3-4단계 이상인 자 5) 본 연구의 자발적인 참여 자로 동의서에 서명을 받은 자로 연구를 수행하였다. 대상 자 제외조건은 다음과 같다 1) 근골격계 및 심혈관계 질환 자, 2) 시각 장애자, 3) 피부 질환 대상자는 제외하였다.

\section{연구절차}

제비 뽑기를 이용하여 무작위로 실험군 $(\mathrm{n}=21)$, 대조군 $(\mathrm{n}=21)$ 으로 분류하였다. 모든 대상자는 실험 전과 4 주 후 운동기능, 하지 근력, 그리고 보행 능력을 측정하였다. 두 군 모두 4 주간 주 5 회, 하루에 30 분간 훈련을 적용하 였다. 단일 맹검법을 적용하여 대상자들은 그룹의 대해 알지 못한 상태에서 임상경력 3년차 이상인 물리치료사가
훈련을 진행하였다.

\section{중재방법}

실험군은 발목 관절의 앞정강근의 키네시오 테이핑을 병행한 트레드밀 보행훈련을 실시하였다. 보행속도는 환 자의 보행 패턴을 분석하여 하지의 보상 작용이 나타나지 않는 범위 내에서 주당 $0.1 \mathrm{~m} / \mathrm{s}$ 씩 속도를 조절하였으며 20 초간 안정적인 보행을 실시할 경우 보행 속도를 유지 하였다[19,20]. 앞정강근의 키네시오 테이핑 적용은 수동 적으로 환자의 발목을 최대한 발목 관절의 발등 굽힘을 한 상태에서 I형 스트립 테이핑의 길이를 $15 \sim 30 \%$ 늘린 상태에서 발등의 중족부(mid-foot)에서 정강뼈 거친면의 위쪽에 일자로 부착하였다. 그런 다음 물리치료사는 환자 의 발목을 최대한 발바닥 굽힘을 하고 난 후 중간 부분의 테이핑을 피부에 접촉하였다. 두 번째 I형 스트립 테이핑 은 정강이뼈 조면(tibial tuberosity)외측 부분에 가로로 부착하였다 $[21,22]$. 대조군은 정강이뼈와 발목 관절에 두 줄로 가로 방향으로 위약 테이핑을 적용한 상태에서 트레 드밀 보행훈련을 실시하였다. 트레드밀 환경은 실험군과 대조군 모두 같은 동일한 환경에서 적용하였다. 키네시오 테이핑은 실험기간동안에 착용하였고, 2 일에 한번씩 키네 시오 테이핑 교체하여 다시 적용하였다. 한 명의 물리치 료사는 트레드밀 옆에서 낙상을 예방과 위급한 상황이 발 생하면 중지할 수 있도록 응급정지버튼에 손을 올려놓고 적절한 음성지시를 통해 대상자의 보행패턴을 촉진하였 다[23].

\section{측정방법 및 도구}

뇌졸중 환자의 운동기능을 평가하기 위해 Fugl-meyer assessment를 이용하였으며, Fugl-meyer assessment의 하지 항목은 총 17 개로 구성되어 있으며, 최대점수는 34 점이다. Fugl-meyer assessment의 평가자 간 신뢰도는 r $\geq .96$ 이고, 동시타당도 $r \geq 96$ 으로 신뢰할 수 있는 평가방법 이다[24]. 하지 근력검사는 디지털 근력계를 사용하며, 연 구 대상자의 앉은 자세에서 발목 관절 발등 굽힘근의 근 력을 측정하였다. 디지털 근력계는 $\mathrm{r}=0.90 \sim 0.96$ 의 신뢰 도를 가지고 있으며, $99 \%$ 의 정확도를 가지고 있다[25]. 보행 변수는 보행분석기(G-walk, BTS Bioengineering inc., Milan, Italy)를 사용하여 보행의 시공간적 요소를 평가하였다. 변수로는 활보장, 보행속도, 그리고 분속수를 측정하였다. 측정방법은 $\mathrm{G}$-센서를 허리뼈 5 번(L5)과 엉치 뼈 1번(S1)에 위치하여 벨트를 고정시킨 후 편안한 속도 로 $8 \mathrm{~m}$ 를 걸으면서 보행의 변수를 수집하였다. 보행분석 기는 몸통 가속도계와 동작분석기의 상관계수는 $r=0.93$ (왼발), $\mathrm{r}=0.90$ (오른발)으로 높은 상관계수를 가지고 있 
다[26]

\section{자료분석}

SPSS(Version 20.0, Chicago, Illinoi)을 이용하여 통 계적 분석을 실시하였다. Shapori-Wilk검정을 통해 정규 성 검정을 하였다. 대응표본 t검정을 사용하여 각 그룹 내 훈련에 따른 종속변수의 전후차이를 비교하였다. 독립표 본 t검정을 사용하여 각 그룹 간 훈련방법에 따른 종속변 수의 변화량을 비교하였다. 모든 통계학적 유의수준 $(\alpha)$ 은 0.05 이하로 설정하였다.
연구대상의 일반적인 특성은 Table 1 과 같다. 두 그룹 모두 일반적인 특성에 동질하게 나타났다 $(\mathrm{p}>0.05)$.

\section{연구결과}

\section{연구대상자의 일반적인 특성}

Table 1. General Characteristics of Participants

$(\mathrm{n}=42)$

\begin{tabular}{llll}
\hline & Experimental group $(\mathbf{n = 2 1})$ & Control group $(\mathbf{n}=\mathbf{2 1})$ & $\mathbf{p}$ \\
\hline Gender (male/female) & $12 / 9$ & $9 / 12$ & $0.537^{\mathrm{a}}$ \\
\hline Etiology (infarction/hemorrhage) & $10 / 10$ & $12 / 9$ & $0.539^{\mathrm{a}}$ \\
\hline Affected side (left/right) & $10 / 11$ & $13 / 8$ & $0.535^{\mathrm{a}}$ \\
\hline Age (year) & $55.52(8.61)$ & $59.10(6.82)$ & $0.144^{\mathrm{b}}$ \\
\hline Height (cm) & $165.73(7.70)$ & $166.07(4.69)$ & $0.866^{\mathrm{b}}$ \\
\hline Weight (kg) & $67.22(10.15)$ & $69.37(9.22)$ & $0.477^{\mathrm{b}}$ \\
\hline Duration (month) & $10.33(2.29)$ & $10.10(2.10)$ & $0.727^{\mathrm{b}}$ \\
\hline K-MMSE (score) & $26.67(1.46)$ & $27.10(1.41)$ & $0.339^{\mathrm{b}}$ \\
\hline
\end{tabular}

The values are presented mean (SD). aChi-square test. bIndependent t-test.

Experimental group: Treadmill training with kinesio taping of tibialis anterior, Control group: Treadmill training with sham kinesio taping of tibialis anterior.

K-MMSE, Korean mini-mental state examination.

Table 2. Comparison of motor function

$(\mathrm{n}=42)$

\begin{tabular}{lllll}
\hline & & Experimental group $(\mathbf{n}=21)$ & Control group $(\mathbf{n}=\mathbf{2 1})$ & t $(\mathbf{p})$ \\
\hline & Pre & $20.71(2.08)$ & $20.62(1.86)$ & 0.876 \\
\cline { 2 - 5 } Fugl Myer assessment (score) & Post & $24.14(1.42)$ & $22.19(1.89)$ & $0.000^{*}$ \\
\cline { 2 - 5 } & $\Delta$ & $-3.43(1.43)$ & $-1.57(0.68)$ & \\
\cline { 2 - 5 } & $\mathrm{t}(\mathrm{p})$ & $-10.954\left(0.000^{*}\right)$ & &
\end{tabular}

The values are presented mean (SD)

Experimental group: Treadmill training with kinesio taping of tibialis anterior, Control group: Treadmill training with sham kinesio taping of tibialis anterior.

${ }^{*} \mathrm{p}<0.05$ 
Table 3. Comparison of muscle strength

$(\mathrm{n}=42)$

\begin{tabular}{|c|c|c|c|c|}
\hline & & Experimental group $(n=21)$ & Control group $(n=21)$ & $t(p)$ \\
\hline \multirow{4}{*}{ Muslce Strength (kg) } & Pre & $4.81(0.66)$ & $4.75(0.53)$ & 0.757 \\
\hline & Post & $5.45(0.67)$ & $5.12(0.51)$ & \\
\hline & $\Delta$ & $-0.64(0.35)$ & $0.37(0.34)$ & $0.013^{*}$ \\
\hline & $t(p)$ & $-8.347\left(0.000^{*}\right)$ & $-4.966\left(0.000^{*}\right)$ & \\
\hline
\end{tabular}

The values are presented mean (SD)

Experimental group: Treadmill training with kinesio taping of tibialis anterior, Control group: Treadmill training with sham kinesio taping of tibialis anterior.

${ }^{*} \mathrm{p}<0.05$

Table 4. Comparison of muscle strength

$(\mathrm{n}=42)$

\begin{tabular}{|c|c|c|c|c|}
\hline & & Experimental group $(n=21)$ & Control group $(n=21)$ & $t(p)$ \\
\hline \multirow{4}{*}{ Cadence (steps/min) } & Pre & $66.96(7.42)$ & $67.83(6.46)$ & 0.689 \\
\hline & Post & $72.62(8.91)$ & $69.62(6.31)$ & \\
\hline & $\Delta$ & $5.66(4.02)$ & $1.79(3.42)$ & $0.002^{*}$ \\
\hline & $t(p)$ & $-6.448\left(0.000^{*}\right)$ & $-2.401\left(0.026^{*}\right)$ & \\
\hline \multirow{4}{*}{ Gait velocity (m/sec) } & Pre & $45.07(4.47)$ & $46.60(4.73)$ & 0.287 \\
\hline & Post & $48.60(4.30)$ & $48.19(5.35)$ & \\
\hline & $\Delta$ & $3.53(3.05)$ & $1.59(1.68)$ & $0.014^{*}$ \\
\hline & $t(p)$ & $-5.301\left(0.000^{*}\right)$ & $-4.328\left(0.000^{*}\right)$ & \\
\hline \multirow{4}{*}{ Stride length $(\mathrm{cm})$} & Pre & $75.47(6.81)$ & $77.98(7.37)$ & 0.258 \\
\hline & Post & $79.33(4.73)$ & $79.64(7.06)$ & \\
\hline & $\Delta$ & $3.86(3.97)$ & $1.66(2.58)$ & $0.039^{*}$ \\
\hline & $t(p)$ & $-4.461\left(0.000^{*}\right)$ & $-2.949\left(0.008^{*}\right)$ & \\
\hline
\end{tabular}

The values are presented mean (SD)

Experimental group: Treadmill training with kinesio taping of tibialis anterior, Control group: Treadmill training with sham kinesio taping of tibialis anterior.

${ }^{*} \mathrm{p}<0.05$

\section{운동기능 전 · 후 변화}

운동기능 변화에 대한 그룹 내 실험 전·후를 비교한 결과, 통계학적으로 유의한 차이를 보였다 $(\mathrm{p}<0.05)$. 두 그룹 간의 운동기능 변화량에서, 실험군이 대조군보다 통 계학적으로 증가한 것으로 나타났다 $(\mathrm{p}<0.05)$.

\section{하지 근력 전 · 후 변화}

하지 근력 변화에 대한 그룹 내 실험 전·후를 비교한 결과, 통계학적으로 유의한 차이를 보였다 $(\mathrm{p}<0.05)$. 두 그룹 간의 하지 근력 변화량에서, 실험군이 대조군보다 통계학적으로 증가한 것으로 나타났다 $(\mathrm{p}<0.05)$.

\section{보행능력 전 · 후 변화}

활보장, 보행속도, 그리고 분속수 변화에 대한 그룹 내 실험 전·후를 보행능력을 비교한 결과, 통계학적으로 유 의한 차이를 보였다 $(\mathrm{p}<0.05)$. 두 그룹 간의 활보장, 보행 속도, 그리고 분속수 변화량에서 실험군이 대조군보다 통 계학적으로 증가한 것으로 나타났다 $(\mathrm{p}<0.05)$.

\section{고찰}

본 연구는 만성 뇌졸중 환자의 하지기능, 균형 그리고 보행능력에 미치는 영향을 알아보기 위하여 선행 연구를 기반으로 키네시오 테이핑을 병행한 트레드밀 보행훈련을 
실시하였으며, 그 결과 뇌졸중 환자의 하지기능, 균형 그 리고 보행능력에 긍정적 영향이 있음을 확인하였다.

뇌졸중 환자의 고유수용성 감각은 감각-운동계의 핵심 적 구성요소로, 신경근의 조절을 위한 구심성 정보를 중 추신경계에 제공함과 동시에 동적 관절 안정성에 기여한 다[27]. 본 연구에서의 키네시오 테이핑을 병행한 트레드 밀 보행훈련은 발목관절의 고유수용성 감각-운동 시스템 의 활성화에 기여를 함으로써 하지의 기능 증진에 긍정적 인 영향을 나타났다고 생각된다.

본 연구에서 운동기능의 변화는 군내, 군간 모두 유의 한 증가가 나타났다. 특히, 운동기능의 변화량에서 실험군 이 대조군보다 통계학적으로 유의한 차이를 보였다.

Wang 등 [28]의 체계적인 고찰 논문에서 하지의 키네 시오 테이핑 적용이 하지의 운동기능, 균형, 보행능력 등 에 부작용 없이 유의하게 개선되었다는 논문과 일치한다. 키네시오 테이핑 훈련과 운동 재학습을 결합한 그룹이 운 동 재학습 그룹 보다 경직성을 동반하는 뇌졸중 환자에게 서 효과적이라고 보고하였다[29]. In 등[30]의 연구에서 30 명의 뇌졸중 환자를 대상으로 세라밴드를 결합한 트레 드밀 보행훈련군과 트레드밀 보행훈련군으로 1 주일 5 번, 총 4주간의 훈련을 실시한 결과 운동기능에 유의한 향상 을 보였다. 이는 키네시오 테이핑의 근력 증진과 반복적 인 트레드밀 보행훈련을 통해서 뇌졸중 환자의 운동학습 능력이 증가되어 하지의 운동기능이 향상되었다고 사료된 다. 또한 키네시오 테이핑과 트레드밀 감각입력으로부터 앞정강근의 근방추와 힘줄에 작용하여 운동기능 향상 되 었으며 관절과 근육의 움직임을 활성화하여 운동기능을 촉진하였다고 생각된다.

균형 능력은 뇌졸중 이후 뇌졸중 환자의 기능적 회복의 척도로 중요한 예상요인으로 쓰이며[31], 이에 따라 뇌졸 중 환자의 다양한 치료목표 중 균형 능력 향상과 기능 개 선이 그 중 하나라고 할 수 있다[32]. Kim 등[14]의 연구 에서 33명의 뇌졸중 환자를 대상으로 발목관절과 앞정강 근의 키네시오 테이핑의 즉각적 효과를 알아본 결과 이동 성과 균형에 향상되었다는 논문과 일치한다. Park과 Eo [33]은 뇌졸중 환자에게 키네시오 테이핑 적용으로 균형 능력에 증진이 나타났다고 하였다. 본 연구에서 균형능력 의 변화는 실험군에서 군내 군간 모두 유의한 증가가 나 타났으며, 이러한 결과로 키네시오 테이핑을 병행한 트레 드밀 보행훈련은 뇌졸중환자에게 의미 있는 증진을 가져 오는 것으로 확인되었다. 이는 발목과 무릎에 테이핑을 하면 각 관절의 안정성을 높이고 피부 수용체의 신경 촉 진을 유도하기 때문일 수 있다고 한 선행연구와 같이[34], 본 연구의 키네시오 테이핑을 병행한 트레드밀 보행훈련 에 의해 균형능력에 증진이 나타난 것으로 사료된다. 또 한 앞정강근의 테이핑이 균형의 운동전략인 발목전략을
활성화여 균형능력이 증진되었다고 사료된다.

본 연구에서 보행능력의 변화는 실험군에서 군내, 군간 모두 유의한 증가가 나타났다. Wade과 Hewer[35]의 연 구에서 보행이 만성 뇌졸중 환자에서 가장 어려운 문제로 생각하였다. Scherer[36]은 뇌손상 진단을 받은 환자를 대 상으로 체중지지 트레드밀 보행 훈련을 적용하여 보행능 력이 향상되었다. Jeong 등[37]의 연구에서 뇌졸중 편마 비 환자에게 트레드밀 훈련 및 PNF 테이핑을 적용하여 보행의 증진이 나타났다고 하였다. 뇌졸중 환자의 보행 시 짧은 유각기를 트레드밀 훈련으로 마비 측 엉덩관절의 빠른 폄을 통해 엉덩관절 굽힘 반사를 일어나도록 유도하 고[38], 증가된 가동 범위의 엉덩관절 굽힘 보행은 대칭적 이고 효율적인 보행 패턴을 만들어, 선행연구[39]와 같이 본 연구의 활보장의 향상이 나타난 것으로 보인다. 키네 시오 테이핑을 병행하여 트레드밀 훈련 시 하지의 안정성 과 근육의 활성도가 증가하며, 특히 폄근의 활동이 증가 하여 올바른 체중지지로 발목관절의 움직임을 많이 사용 하기 때문에 보행능력의 향상이 가져 온 것으로 사료된다.

본 연구의 제한점으로는 대상자의 일상생활에 대하여 완전히 통제할 수 없어 연구의 종속 변수에 영향이 미칠 수 있음을 완전히 배제할 수 없으며, 연구의 선정기준을 통하여 대상자를 선정하여 본 연구를 실시하여 결과를 모 든 만성 뇌졸중 환자의 하지기능, 균형, 보행에 일반화하 여 해석하는 것에 제한이 있다는 것이다. 앞으로는 다양 한 키네시오 테이핑 적용, 다양한 대상자 선정과 평가 도 구를 고려하는 등 추가적 연구가 필요하다고 사료된다.

\section{결론}

본 연구에서는 키네시오 테이핑을 결합한 트레드밀 보 행훈련이 만성 뇌졸중 환자의 하지 기능, 균형, 그리고 보 행능력에 미치는 효과를 알아보았다. 본 연구결과 키네시 오 테핑을 결합한 트레드밀 보행훈련이 대조군 보다 하지 기능, 균형, 그리고 보행능력에 긍정적인 영향을 미침을 확인하였다. 따라서 뇌졸중 환자의 키네시오 테이핑과 관 련하여 피부계 질환의 문제점이 없다면 하지기능, 균형, 그리고 보행능력을 증진시키기 위해 키네시오 테이핑을 병행한 트레드밀 보행훈련이 임상에서 중요한 중재방법으 로 사용될 것이다.

\section{이해충돌}

본 연구의 저자들은 연구, 저자권, 및 출판과 관련하여 잠재적인 이해충돌이 없음을 선언합니다. 


\section{참고문헌}

1. Warlow CP, Van Gijn J, Dennis MS, Wardlaw JM, Bamford JM, Hankey GJ, et al. Stroke: practical management. John Wiley \& Sons. 2011

2. Hase K, Suzuki E, Matsumoto M, Fujiwara T,Liu M. Effects of therapeutic gait training using a prosthesis and a treadmill for ambulatory patients with hemiparesis. Arch Phys Med Rehabil. 2011;92(12): 1961-6

3. Lord SE, Mc Pherson K, Mc Naughton HK, Rochester L, Weatherall M. Community ambulation after stroke: How important and obtainable is it and what measures appear predictive? Arch Phys Med Rehabil. 2004;85(2):234-9

4. Kwon OH, Woo YK, Lee JS, Kim KH. Effects of task-oriented treadmill-walking training on walking ability of stoke patients. Top Stroke Rehabil 2015 22(6), 444-452

5. Kim KH, Lee KB, Bae YH, Fong SS, Lee SM. Effects of progressive backward body weight supported treadmill training on gait ability in chronic stroke patients: a randomized controlled trial. Technology and Health Care 2017; 25(5):867-76

6. Luft AR, Macko RF, Forrester LW, Villagra F, Ivey $\mathrm{F}$, et al. Treadmill exercise activates subcortical neural networks and improves walking after stroke: a randomized controlled trial. Stroke 2008;39(12):3341-50

7. Dorfman $M$, Herman $T$, Brozgol $M$, Shema $S$, Weiss A, et al. Dual-task training on a treadmill to improve gait and cognitive function in elderly idiopathic fallers. J Neurol Phys Ther 2014;38(4):246-53

8. Sousa AVCD, Santiago LMDM, Silva REDOD, Oliveira DAD, Galvã ÉVP, Lindquist ARR. Influence of treadmill training in dual-task gait in people with Parkinson's Disease: a case report. Fisioterapia epesquisa 2014;21:291-6

9. Hesse $\mathrm{S}$, Werner $\mathrm{C}$, Bardeleben $\mathrm{A}$, Barbeau $\mathrm{H}$. Body weight-supported treadmill training after stroke. Curr Atheroscler Rep 2001;3(4):287-94.

10. Kase, K. Kinesio taping. Illustrated Kinesio Taping. Tokyo: Ken Ikai Information, 6-12. 2003

11. Kalron A, Bar-Sela, S. A systematic review of the effectiveness of Kinesio Taping--fact or fashion. Eur J Phys Rehabil Med 2013;49(5):699-709

12. Refshauge KM, Kilbreath SL, Raymond J. The ef- fect of recurrent ankle inversion sprain and taping on proprioception at the ankle. Med Sci Sports Exerc 2000;32:10-5

13. Lynch EA, Hillier SL, Stiller K, Campanella RR, Fisher PH. Sensory retraining of the lower limb after acute stroke: a randomized controlled pilot trial Arch Phys Med Rehabil 2007;88(9):1101-7

14. Kim KH, Lee YJ. Immediate Effects of Kinesio Taping of Tibialis Anterior and Ankle Joint on Mobility and Balance Ability for Chronic Hemiparesis: Randomized Controlled Cross-Sectional Design. Physikalische Medizin, Rehabilitationsmedizin, Kurortmedizin, 2020;30:350-7

15. Hu Y, Zhong D, Xiao Q, Chen Q, Li J, Jin R. Kinesio taping for balance function after stroke: a systematic review and meta-analysis. Evid Based Complement Alternat Med, 2019;jul16:8470235

16. Kase K, Hashimoto T. Changes in the volume of the per ipheral blood flow by using kinesio taping. Kinesio Taping As sociation 1998;82:1373

17. Fu TC, Wong AM, Pei YC, Wu KP, Chou SW, Lin YC. Effect of Kinesio taping on muscle strength in athl etesa pilot study. J Sci Med sport 2008; 11(2):198-201

18. Yasukawa A, Patel P, Sisung C. Pilot study: Investigatin $g$ the effects of Kinesio Taping in an acute pediatric rehabilitation setting. Am J Occup Ther 2006;60(1):104-10

19. Cho KH, Lee WH. Effect of treadmill training based real-world video recording on balance and gait in chronic stroke patients: A randomized controlled trial. Gait Posture 2014;39(1);523-8

20. Kim KH, Lee KB, Bae YH, Fong SSM, Lee SM. Effects of progressive backward body weight supported treadmill training on gait ability in chronic stroke patients: A randomized controlled trial. Technol Health Care 2017;25(5):867-76

21. Koseoglu BF, Dogan A, Tatli HU, Ozcan DS, Polat CS. Can kinesio tape be used as an ankle training method in the rehabilitation of the stroke patients? Complement Ther Clin Pract 2017;27:46-51

22. Halseth T, McChesney JW, DeBeliso M, Vaughn R, Lien, J. The effects of kinesio ${ }^{\mathrm{TM}}$ taping on proprioception at the ankle. J Sports Sci Med 2004; $3(1): 1-7$

23. Kim KH, Lee SM, Lee, KB. Effects of progressive 
body weight support treadmill forward and backward walking training on stroke patients' affected side lower extremity's walking ability. J Phys Ther Sci 2014; 26(12):1923-7

24. Sanford J, Moreland J, Swanson LR, Stratford PW, Gowland C. Reliability of the Fugl-Meyer assessment for testing motor performance in patients following stroke. Phys Ther 1993;73:447-54

25. Koblbauer IF, Lambrecht Y, van der Hulst ML, Neeter C, Engelbert RH, Poolman RW, et al. Reliability of maximal isometric knee strength testing with modified hand-held dynamometry in patients awaiting total knee arthroplasty: useful in research and individual patient settings? A reliability study. BMC Musculoskeletal Disorders 2011;12:1

26. Lee HK, Hwang SJ, Cho SP, Lee DR, You SH, Lee KJ, et al. Development of a novel step detection algorithm for gait evaluation of patients with hemiplegia based on trunk accelerometer. J Biomed Eng Res 2009;30:213-20

27. Lephart SM, Pincivero DM, Giraido JL, Fu FH. The role of proprioception in the management and rehabilitation of athletic injuries. J Sports Med, 25:130-7

28. Wang M, Pei ZW, Xiong BD, Meng XM, Chen $\mathrm{XL}$, Liao WJ. Use of Kinesio taping in lower-extremity rehabilitation of post-stroke patients: A systematic review and meta-analysis. Complement Ther Clin Pract 2019;35:22-32

29. Lerma Castañ PR, Rodríuez Laiseca YA, Montealegre Suáez DP, Castrilló Papamija DB, Losada Urriago GE. Effects of kinesiotaping combined with the motor relearning method on upper limb motor function in adults with hemiparesis after stroke. J Bodyw Mov Ther 2020;24:546-53

30. In TS, Jin YM, Jung KS, Cho HY. Treadmill training with thera-band improves motor function, gait and balance in stroke patients. NeuroRehabiltation 2017;40:109-14

31. Duarte E, Marco E, Muniesa JM, Belmonte R, Diaz $\mathrm{P}$, Tejero $\mathrm{M}$, et al. Trunk control test as a functional predictor in stroke patients. J Rehabil Med 2002;34:267-72

32. Tyson SF, Hanley M, Chillala J, Selley A, Tallis RC. Balance disability after stroke. Phys Ther 2006; $86: 30-8$
33. Park YH, Eo YS. Effect of Kinesio Taping Method on Ankle Muscle Tone, Balance Ability and Range of Motion in Chronic Stroke Patients. J Korea Soc Phys Med 2021;16:83-92

34. Lee MS, Lee JH, Park SK, Kang JI. (2012). The effect of ankle joint taping applied to patients with hemiplegia on their gait velocity and joint angles. J Korean Phys Ther 2012;24:157-62

35. Wade DT, Hewer RL, Functional abilities after stroke: measurement, natural history and prognosis. J Neural Neurosurg Psychiatry 1987;50:177-82

36. Scherer M. Gait rehabilitation with body weight-support treadmill training for a blast injury survivor with traumatic injury. Brain Inj 2007;21: 93-100

37. Jeong WM, Kim BR, Kang MK. Effect of Treadmill Training and Proprioceptive Neuromuscular Facilitation Lower Leg Taping on Balance and Gait Ability in Stroke Patients. PNF Mov 2016;14:83-91

38. Visintin M, Barbeau H. The effects of body weight suport on the locomotor pattern of spastic paretic patients. Can J Neur ol Sci 1989;16:315-25

30. Lau KW, Mak MK. Speed-dependent treadmill training is effective to improve gait and balance performance in patientswith sub-acute stroke. J Rehabil Med 2011;43:709-13 